\title{
The Central Role of Imagination in Linguistics, Philosophy and Logic
}

\author{
Esa Itkonen
}

\begin{abstract}
Imagination is often accused of being "vulnerable", or even downright unrealizable as a source of knowledge. I argue that this is mistaken, at least for some kinds of systematic imagination. First, imagination is shown to be key for the notion of entailment, which is central in philosophical and linguistic semantics, and in logic. Further, I show how such a non-psychological notion of imagination vindicates so-called "Objectivism", attacked in cognitive linguistics. There are indeed limits to imagination, related to contradiction and ontological puzzles, but once handled with care, such limits do not invalidate it either. In sum, despite scepticism about imagination from Aristotle to the present, I show that it is if fact inevitable, intimately linked with normativity and rationality.
\end{abstract}

Keywords: intuition, normativity, Objectivism, ontology, rationality

\section{Introduction}

Let us start by outlining a preliminary taxonomy of acts of gaining new information. There is, first of all, the dichotomy between observation (sense-perception) and everything else. Second, qua subtypes of non-observation, a distinction has to be made between intuition (about [exemplifications of] intersubjective or socially valid norms) and introspection (of subjective contents of consciousness). Third, for use in action-explanations, we need to postulate empathy as another type of non-observation, namely as a kind of "vicarious introspection". Finally, theoretical reflection, regardless of whether it applies to results of observation, intuition, introspection, or empathy, must ex definitione be a subtype of nonobservation. More fine-grained taxonomies are certainly feasible.

Ever since the early 1970 's, I have dealt with these fundamental notions in numerous publications. ${ }^{1}$ It is only recently that I became aware of the following lacuna in my overall account: there is no systematic place for the (multifarious) notion of imagination. Obviously, this situation needs to be rectified.

I became aware of the importance of imagination only after I encountered claims that are supposed to show its unimportance, such as the following by Thompson and Hopper (2001, emphasis added): "The methodology for determining semantic valence is vulnerable. The linguist introspects about imagined or conceptualized 'scenes' for verbs and who or what must be present or 'on the stage' with that verb" (p. 41) and "What has been discussed as 'valence' or 'argument structure' may be better captured ... without trying to imagine scenes or participants" (p. 50). What started as a brief critical note on Thompson and Hopper's data-oriented position rapidly acquired a momentum of its own and has by now become a full-length article.

The structure of the paper is following. In Section 2, as a preliminary step for the argument of the centrality of imagination in linguistics, philosophy and logic, I discuss the notion of entailment in both the philosophical and linguistic semantics literature. In Section 3 , I show how this explicitly connects to imagination, again both in philosophical and linguistic semantics. Section 4 turns to the role of imagination in logic. In Section 5, I show how such a non-psychological notion of imagination vindicates so-called "Objectivism",

\footnotetext{
${ }^{1}$ For a summary, see Itkonen (2013, pp. 58-60).
} 
attacked by Mark Johnson and George Lakoff. In Sections 6 and 7 I discuss a number of different kinds of limits to imagination, related to contradiction and to various ontological puzzles. Section 8 presents some historical context, and the argument on the centrality of imagination is rounded off in Section 9.

\section{Entailment as the basis of semantic analysis ${ }^{2}$}

Pap (1958, p. 92) has claimed that: "the concept of entailment (and the related concepts of logical contradiction and logical incompatibility) is the primary tool by means of which analytical philosophers undertake to analyse concepts". This claim may be illustrated by the classical definition of "knowledge" as "true justified belief", which goes back to Plato's Meno (97b-100a) and Theaetetus (201a-210d). This concept can be interpreted as having been elicited by different types of entailments, such as those in (1-3).

(1) If $\mathrm{X}$ knew that $\mathrm{p}$, then $p$ was true.

(2) If $\mathrm{X}$ correctly guessed that $\mathrm{p}$, then $\mathrm{X}$ had a true belief concerning $p$ (but $\mathrm{X} \operatorname{did}$ not know that $\mathrm{p}$ ).

(3) If $\mathrm{X}$ believed that $\mathrm{p}$, when $p$ was highly probable and yet false, then $\mathrm{X}$ had a justified belief concerning $p$ (but $\mathrm{X}$ did not know that $\mathrm{p}$ ).

The entailment in (2) shows that "knowledge = true belief" is not enough, while (3) shows that "knowledge $=$ justified belief" is not enough. What is required is "true justified belief". Notice, however, that there is no cogent reason to formulate this definition as an equivalence: " $\mathrm{X}$ knows that $\mathrm{p}$ if, and only if, $\mathrm{X}$ has a true justified belief concerning $p$ "; it is enough to formulate it as an implication, i.e. as stating a necessary condition for 'knowledge': "If X knows that $\mathrm{p}$, then $\mathrm{X}$ has a true justified belief concerning $p$ " (which is logically equivalent to "Only if $\mathrm{X}$ has a true justified belief concerning $p$, does $\mathrm{X}$ know that p"). It would be imprudent to formulate our definition as a sufficient condition for "knowledge": "If $\mathrm{X}$ has a true justified belief concerning $p$, then $\mathrm{X}$ knows that $\mathrm{p}$ ", since Gettier (1967/1963) has managed to contrive a counter-example to the equivalence, i.e. a case where $\mathrm{X}$ has a true justified belief concerning $p$ and yet does not know that $\mathrm{p}$ (for discussion, cf. Lehrer, 1974, pp. 14-18).

More generally, it is primarily (but not exclusively) by means of such entailments (and contradictions) that we perform each and every semantic analysis, whether or not we realize it (and even contrary to explicit denials). First, consider such lexical meanings as those of father and to run. How do we know that a father denotes a male parent (plus, perhaps, something else) or that running denotes a kind of motion? By means of entailments like (4)-(6) and contradictions like (7)-(9):

(4) If $X$ is $Y$ 's father, then $X$ is male.

(5) If $X$ is Y's father, then $X$ is Y's parent.

(6) If $X$ is running, then $X$ is moving.

(7) *If $X$ is $Y$ 's father, then $X$ is female.

(8) *If $X$ is Y's father, then $X$ is Y's child.

(9) *If $X$ is running, then $X$ is motionless.

\footnotetext{
${ }^{2}$ The discussion in this section assumes the following definitions: " $p$ is possibly true" $=$ " $p$ is not necessarily false"; " $p$ is necessarily true" = "it is not possible (i.e. it is impossible) that $p$ is false"; "analytic" = "necessarily true"; "(self-)contradictory" = "necessarily false"; "synthetic/contingent" = "neither analytic nor contradictory"; "implication" = if $p$, then $q$; "entailment" = "analytic implication".
} 
Second, consider such grammatical meanings as Singular (vs. Plural) and Present (vs. Past). How do we become aware of their existence? By means of entailments like (10)(11) and contradictions like (12)-(13).

(10) If $X$ met a friend, then $X$ met one person.

(11) If $X$ is running, then it happens now.

(12) *If X met a friend, then X met several persons.

(13) *If $X$ is running, then it happened yesterday.

We may summarize with the words of Edgley (1970, p. 25): "In learning the meanings of words, we in effect learn certain simple analytical truths; for these truths are simple in this way, that knowing them to be [necessarily] true is a necessary condition of understanding their meaning". Indeed, these truths are so obvious that we tend to forget them. Or worse, we tend to think that they have somehow been superseded by the latest results of empirical (i.e. observation-based) research. In the context of the present argument, entailment is rather related to imagination.

\section{Imagination in semantics ${ }^{3}$}

The notion of analyticity/entailment (see footnote 2) has been the object of much discussion. As argued by Pap (1958, p. 371), on the one hand, there are absolutely clear cases of analyticity/entailment, as shown by (14); on the other, the analytic-synthetic distinction is a gradual one, as shown by the scale $(14)<(15)<(16){ }^{4}$

If $\mathrm{X}$ is red, then $\mathrm{X}$ is coloured.

- clearly analytic

\footnotetext{
${ }^{3}$ The following additional definitions are assumed: "imaginable" = "conceivable" = "possible"; "it can be imagined that $\mathrm{p}$ and that not-p" = "it is possible that p"; "it cannot be imagined that p" = "it is impossible that p"; "it cannot be imagined that not-p" = "it is necessary (i.e. necessarily true) that p". Notice also that it can be imagined that $p$ both if it is necessary that $p$ and if it is possible that $p$.

${ }^{4}$ In 400-plus pages, Pap (1958) constructs an elaborate, occasionally repetitious argument against Rudolf Carnap and other "enemies of intuition". He imagines the following objection: "But there is no ... agreement among various philosophers' intuitions as to which propositions are necessary, which entail which, and which are compatible with which. That's why an analytic philosophy based on alleged intuitions of logical necessity and possibility is really based on quicksand" (p. 420). This is his more than adequate reply: "It is true that the meanings of philosophically interesting terms of everyday language and even of scientific language are sufficiently inexact to allow considerable leeway in the choice of criteria of adequacy. But, on the other hand, they are also sufficiently definite to impose some criteria of adequacy as statements [elsewhere: pre-analytic entailments] which cannot be denied without changing the ordinary meanings of their terms" (p. 417). Arguably, this standpoint of "moderate intuitionism" is the only viable approach to philosophical semantics. What are the alternatives? On the one hand, (all-out) formalism is based on a simple logical error: "Whatever the merits of this Carnapian method of analysis may be, it must be conceded that it is intuitive necessity of propositions which guides the selection of the material criteria of adequacy for a given explication, and if this is denied, explications appear as either circular or as philosophically irrelevant" (p. 416; also pp. 396-397; for the notion of explication, see Itkonen, 1978, pp. 301-310). The process of formalization presupposes the existence of some $\mathrm{X}$ (however minimal), which is to be formalized; and X must be assumed to exist, un-formalized, before the process of formalization starts. In semantics, $X$ is a set of pre-theoretical (or 'pre-analytic') entailments. On the other hand, all-out empiricism, i.e. the wholesale attempt to replace philosophy by empirical science (preferably physics), has little intellectual credibility. The analogy between (Pap-type) intuition-based philosophy and (intuition-based) autonomous linguistics was the basic insight of Itkonen (1974). Next, this analogy was extended to formal (= deontic) logic in Itkonen (1975), as summarized in Itkonen (1978, Chap. 10).
} 
(15) If $X$ is a lemon, then $X$ is sour. - not clearly analytic

(16) If $X$ is a lemon, then $X$ is expensive. - clearly synthetic

Pap comments on example (14): "There is nothing gradual about (14), because there is no conceivable situation in which one might be inclined to affirm the antecedent but to deny the consequent" (ibid, p. 371; emphasis added). ${ }^{5}$ With respect to (15), he comments: "I think that (15) is not analytic for most English-speaking people ... - in other words, that (15) is synthetic. But it is conceivable that we should invent a new class term for a species of fruit, i.e. what looks like a lemon but does not taste sour [= 'if $\mathrm{X}$ is not sour, then $\mathrm{X}$ is not a lemon'], which would make (15) analytic, after all" (p.345; emphasis added). In this sense, (15) is analytic, if at all, only in a "gradual" (or "pragmatic") sense. Finally, a sentence like (16) - not explicitly discussed by Pap (1958) - is clearly synthetic, because it is either true or false depending on the context.

Several things need to be noticed here. First, the key term conceivable is synonymous with imaginable. Hence, even the most demanding type of analytical philosophy, epitomized by Pap (1958), turns out to be ultimately based on imagination. Indeed, he very much points that out himself: "Once the relevant meaning of 'imaginable' is circumscribed by excluding the case where it is lack of experience ... that limits the imagination, there is no objection to the imaginability criterion simply because there is no alternative to it" (ibid, p. 218). Wittgenstein (1958a/1953) also endorses this: "Instead of 'imaginability' one can also say here: representability by a particular method of representation” (p. 120, §397). That is, anything that can be intelligibly discussed must be not just imaginable but also representable in one way or another. If it cannot be represented, there is no reason to believe that it can be imagined.

Second, in the present context, imaginable is in turn synonymous with possible. As summarized by Pap (1958) on the very last page of this monumental work: "Faith in mutual understanding of basic modal notions [= possibility and necessity] is indeed an indispensable presupposition of all analytic philosophy" (p. 422). We now reach the same conclusion as above: all analytical philosophy is based on imagination, because "it is possible that $p "=$ "it can be imagined that not-p (as well as that p)", whereas "it is necessary that $\mathrm{p} "=$ "it cannot be imagined that not-p".

Third, no conceptual analysis is feasible without the analytic-synthetic distinction, with the qualification, to be sure, that this distinction is a gradual one. Thus, there is a continuum extending from clearly analytic/necessary to clearly synthetic/contingent, with logical truths exemplifying the highest degree of analyticity/necessity: "As logical truths are necessary propositions, it cannot be validly inferred from the gradualistic character of analyticity that logical necessity is itself a matter of degree" (Pap, 1958, p. 299). ${ }^{6}$

\footnotetext{
${ }^{5}$ On at least one interpretation, this is patently false. We only need to imagine a person who is either a moron or a self-styled humourist. Then it is not only the case that he might be "inclined" to affirm the antecedent and deny the consequent, but he might actually do so as well. Hence, while it is perfectly possible to affirm the antecedent and to deny the consequent, it is wrong to do so. In one stroke, this reveals the normative basis of philosophical/linguistic semantics, which seems to have been taken for granted to the point of having (almost) come to be forgotten. The normative basis of (language and) linguistics is discussed more generally e.g. in Itkonen (2008a) and (2019).

${ }^{6}$ Interestingly, the cognitive linguist Mark Johnson (1987, p. 167) seems to agree: "we deny the strict separation of the analytic from the synthetic ... [and] we regard these as poles on a continuum". But to repudiate the analytic-synthetic distinction just because of its gradual nature, is a simple mistake, exemplified by claims like the following: "Quine (1953) successfully argued that there is no tenable analytic-synthetic distinction" (Lewandowska-Tomaszczyk, 2007, p. 146). This mistake in turn exemplifies the following more general fallacy: 'If there is no absolute distinction between A and $\mathrm{B}$, there is no distinction between $\mathrm{A}$ and $\mathrm{B}$ '. The incidence of this fallacy in contemporary linguistics has been scrutinized at some length in Itkonen (2016) and (2018). We should heed the
} 
Fourth, there is a very close relation between imagination and intuition. On the one hand, entailments qua the basic tool of philosophical analysis are based on what can or cannot be imagined. On the other hand, "semantic analysis of natural language involves intuitive knowledge of necessary propositions [= entailments \& contradictions]" (Pap, 1958, 396). Hence, intuition and imagination turn out to be (near-)synonymous in the present context. To be sure, philosophical analysis can make no headway unless intuition is "enriched" by means of theoretical reflection: there has to be an ascent from pretheoretical to the theoretical, with the understanding that the scope of intuition is eo ipso enlarged.

Fifth and finally, it should be added that the imaginative tradition of analytical philosophy continues today, for example in the work of Daniel Dennett: "philosophers often indulge in fantasy in their thought experiments" (Dennett, 1991, p. 73). On another occasion he remarks: "It is logically possible that the world was created ten minutes ago, complete with all the purported memories of your past installed in your brain" (Dennett, 2014, p. 285). And his philosophical opponents are easily dismissed as being guilty of "impoverished imagination" (p. 283).

Cruse (2000) also claims the "analytic/necessary vs. synthetic/contingent" distinction to be gradual rather than absolute. More precisely, some if - then sentences are definitely entailments whereas others are less and less so, and Cruse (ibid, pp. 28-31) correctly characterizes entailment as a logical (rather than psychological) relation. Consider the following examples.

(17) If $X$ stopped singing, $X$ did not continue singing.

(18) If $X$ is a cat, then $X$ is an animal.

(19) If $X$ is pregnant, then $X$ is female.
- clearly analytic

- not strictly analytic

- even less strictly analytic

With respect to (17), Cruse (2000) states that "there is no conceivable world or universe in which the words mean what they mean in current English and the entailment does not hold" (p. 54; emphasis added). Hence, this is a clear case of analyticity. Example (18) looks like another clear case, but by straining our imagination, we do find a counterexample: "Suppose one day it was discovered that cats were not animals, as everyone had always thought, but highly sophisticated self-replicating robots" (ibidem). On this (rather extravagant) interpretation, (18) would indeed be false. ${ }^{7}$

Finally, it is common knowledge today that (19) has ceased to be an entailment, due to actual (and not just imaginary) counter-examples. Similarly (4) may no longer qualify as clearly analytic, or - alternatively - the analyticity of (4) must be redefined as timedependent, i.e. as limited to the moment of begetting. Incidentally, as much was implicitly predicted by von Wright (1971, p. 20): "the border between the two categories [= analytic vs. synthetic] has often fluctuated in the course of the historical development of a science..." Let us add a caveat: When dealing with scales like $(14)<(15)<(16)$, or $(17)<$ $(18)<(19)$, we must constantly reckon with the possibility that what we are experiencing is "a failure of imagination, not an insight into necessity" (Dennett, 2014, p. 285).

following words of wisdom from Pap (1958): "Now, I have argued that the necessary-contingent distinction is vague, in the same sense that the bald-nonbald distinction is vague, ..." (p. 376). "But to deny a distinction just because of its vagueness is of course a semantic naiveté of the first order. To say of the given distinction that it is vague is quite compatible with saying that there are cases to which one and only one side of the distinction clearly applies" (p. 401; emphasis added).

7 This argument is a variant of the well-known 'Twin Earth' problem: Let us imagine a planet identical with the Earth, except that a liquid that looks, tastes, and feels like water is not chemically $\mathrm{H}_{2} \mathrm{O}$. Are we or are we not justified to call it water? 


\section{Imagination in logic}

Imagination constitutes the core not just of (analytical) philosophy, but also of (formal) logic. Consider the following inference, known as Disjunctive Syllogism:

$\begin{array}{lll}\mathrm{p} \text { or } \mathrm{q} & \text { more formally: } & \mathrm{p} \vee \mathrm{q} \\ \text { not-p } & & \sim \mathrm{p} \\ \overline{\mathrm{q}} & & \overline{\mathrm{q}}\end{array}$

If, for instance, not- $q$ is substituted for not- $p$ in (20), the inference yields the conclusion $p$ (and not the conclusion $q$ ). Wittgenstein $(1967 / 1956$, p. 82) comments on this as follows: "It must not be imaginable for this substitution in this expression to yield anything else. Or: I must declare it unimaginable. (The result of an experiment, however, can turn this way or that.)" Further on he provides a clarification: "Why are the Newtonian laws not axioms of mathematics? Because we could quite well imagine things being otherwise. ... To say of a proposition 'This could be imagined otherwise' ascribes the role of an empirical proposition to it" (p. 114; emphasis added). Hence, the fundamental divide between empirical and non-empirical turns out to rest on what can or cannot be (consistently) imagined. ${ }^{8}$

An important qualification has to be added immediately. Up to now, we have been dealing with voluntary imagination, i.e. imagination recruited for the purposes of analysis. But involuntary imagination occurs as well, most dramatically in dreams; and its results have nothing to do with the empirical vs. non-empirical distinction (see Section 7.2.4). Further, the appeal to imagination entails no commitment to psychologism in logic and mathematics: "Certainly, the propositions 'Human beings believe that twice two is four' and 'Twice two is four' do not mean the same" (Wittgenstein, 1967/1956: 226). ${ }^{9}$ Endorsing what Descartes says at the beginning of his Meditation VI, Dennett (2014: 288-290) makes a clear distinction between "conceiving-of" and "imagining", with the understanding that the latter must be based on "mental images". This is an unnecessarily narrow interpretation of imagination and elsewhere (e.g. pp. 283-287), it is abandoned by Dennett himself. This is also Wittgenstein's position, as shown by his appeal to imagination in the context of formal logic. It is a general truth that mental images are of little use in formal logic; and besides, Wittgenstein's sceptical attitude vis-à-vis mental images is well-known (cf. Russell, 1984, pp. 197-199). Hence, our basic definition stays: "conceivable" = "imaginable".

However, Wittgenstein's view on what can or must be imagined contains the same ambivalence as Pap's discussed in footnote 5. If not- $q$ is substituted for not- $p$ in (20), it goes without saying that we nevertheless can imagine the conclusion to be $q$ (or anything whatever), and we can even write down the corresponding conclusion; but it would be wrong to do so. The upshot: All the time, we are dealing with correct (results of) imagination, rather than with imagination tout court. Elsewhere Wittgenstein (1967/1956) says exactly the same thing: "A proof shows what ought to come out" (p. 90). This explains, in a nutshell, why psychologism in logic is untenable: a norm (of reasoning) is neither a set of mental events nor reducible to such a set. Let us add that while contradiction is the worst $\sin$ in formal logic, to be avoided at all costs, in a different (e.g.

\footnotetext{
${ }^{8}$ Just as every inference can be transformed into an implication, every valid inference can be transformed into an entailment. Thus, (20) becomes $[(p \vee q) \& \sim p] \mid-q$.

${ }^{9}$ There is a venerable tradition of anti-psychologism in the history of logic, starting with Pierre Abaelard, and continuing with Frege and Husserl (once the latter had renounced psychologism, thanks to the former's influence).
} 
aesthetic) context it might be entirely rational to endorse contradiction (or at least to pretend to be doing so) (cf. Wittgenstein, 1967/1956, p. 106). And in order to illustrate irrationality, it is rational to (pretend to) endorse contradiction.

Let us summarize the results of this and the preceding section. Imagination/intuition (enriched by theoretical reflection) is the principal method both in philosophy and in formal logic (as well as in linguistic semantics). But is this method not "vulnerable", as stated by some? No, since as shown, there simply is no alternative to it. It is a different matter altogether that linguistic semantics may be complemented ad libitum by empirical considerations, such as those of psychology.

\section{Imagination vindicates "Objectivism"}

Prima facie, the notion of imagination that I have been explicating is similar to the one that Johnson (1987) argues for when claiming: "imagination is absolutely central to human rationality" (p. 168). There are, however, major differences. Johnson (p. 166) wonders how imagination can have a "dual nature", as both formal and material, and proposes the following solution: "What if, following the consensus of contemporary analytic philosophy, we deny the strict separation of the analytic from the synthetic, ... and the formal from the material? If we regard these as poles on a continuum, then there is no need to exclude imagination from some supposed pristine realm of ... 'objective structure"' ( $p$. 167). The theoretical burden of exemplifying this "pristine realm of objective structure" is then carried by his construct of image schemata, which are said to be "structures of imaginative activities that can be shared by a community"; they are not "private and tied to the mind that experiences them" (p. 168; original emphasis); "image schemata can have a public, objective character ..." (p. 196; original emphasis).

This is problematic at least for the following reasons. First, Johnson conflates here two distinctions: synthetic vs. analytic, on the one hand, and subjective vs. objective, on the other. There is indeed a gradual transition from synthetic to analytic, or vice versa, as shown by our scales $(14)<(15)<(16)$ and $(17)<(18)<(19)$. But there is no analogous transition, or "ascent" from subjective (= World-2) to objective (= World-3). Second, in claiming that there is an ascent from subjective to objective, Johnson is forced to contradict his own cognitivist or psychologist position. His basic commitment to psychologism (i.e. anti-objectivism) is evident from his (unsuccessful) attempt to reduce formal logic to psychology: "if the force of logic operates to move you to a certain 'place', then you wind up in that place" (p. 64). But he overlooks the normative nature of logic: Much (or most) of the time, you are just too stupid to be "moved" in the right way. Third, in claiming that imagination need not be excluded from the realm of objective structure, Johnson tries to show that his notion of imagination is compatible with Frege's three-level ontology. In so doing he contradicts what he states earlier: "Frege thought he needed this strange third realm to ensure the objectivity of meaning and the universal character of mathematics and logic" (p. xxx; emphasis added). Fourth, image schemata are supposed to be mental structures that lie deep under the level of consciousness, and it makes little sense to claim that such structures are "public" and "shared by a community" (see also Zlatev, 2010). ${ }^{10}$

Similarly to Johnson (1987), Lakoff (1987) targets so-called "Objectivism": "These doctrines have evolved over two millennia; ... We will argue that all of the objectivist doctrines concerning human thought and language are problematic if not downright wrong" (pp. 157-158). Their main claim is that: "Objectivism does not concern itself with human understanding and language use" (Johnson, 1987, p. xxxii). In the $20^{\text {th }}$ century, Objectivism has been represented, according to them, by generative linguistics and analytical

\footnotetext{
${ }^{10}$ See Appendix B for a brief discussion on consciousness.
} 
philosophy, as well as by formal logic in general and possible-worlds semantics in particular.

This characterization of Objectivism is contradicted by a massive amount of facts. Plato's analysis of "knowledge" given in (1)-(3), is in the best Objectivist tradition. Since it deals with knowledge and involves notions like belief and justification, it makes no sense at all to claim that it "does not concern itself with human understanding". Similarly, analytical philosophy has dealt with each and every notion even remotely related to human understanding. Furthermore, possible-worlds semantics has been extensively used to explicate such notions as knowledge, belief, perception, memory, etc. As it was given in (1)-(3), the analysis of "knowledge" remains as valid today as it was in the past. It may need to be slightly modified in the light of Gettier's (1967/1963) counter-example. But it is an elementary mistake to think that this kind of philosophical analysis could be falsified by research on "image schemata" or "conceptual metaphors" (let alone by brain research). Just as clearly, such psychological constructs cannot threaten the validity of the Disjunctive Syllogism, given in (20). In this sense, then, "Objectivism" is vindicated, and permanently so. In Sections 2-4 we have seen that linguistic semantics, analytical philosophy, and formal logic are based on imagination, taken in a non-psychological sense. It follows that imagination (taken in this primary sense) vindicates 'Objectivism', contrary to what Lakoff and Johnson claim: "[A]n adequate account of meaning and rationality (as well as of understanding and communication) awaits a comprehensive theory of imagination" (Johnson, 1987, p. 171). "Once you are compelled by the empirical evidence to abandon literalism and objectivism, the whole house of cards collapses. Anglo-American analytic philosophy becomes untenable, as do other traditional approaches to philosophy" (Johnson and Lakoff, 2002, p. 247).

By offering an inordinately narrow definition of "imagination", Lakoff (1987) makes it look like imagination was always considered as either non-existent or "mere fancy", until his own and Johnson's rehabilitation of it: "[The models proposed by others] do not include any of the 'imaginative' models - metonymic, metaphoric, and image schematic" (p. 117); "... products of the imagination such as metaphor, metonymy, and mental imagery ... are banned from the realm of true concepts" (p. 165); "such imaginative aspects of human psychology as metaphor, metonymy, and mental imagery" (ibidem), "concepts ... which are a result of the human imaginative capacity: cognitive models involving metaphor and metonymy" (p. 309); "Reason is imaginative in the sense that it makes use of metonymies, metaphors, and a wide variety of image schemas, ... Imagination is not mere fancy, ..." (p. 368). There is no end to similar passages. But are they true? Let us just have a quick look at what William Dwight Whitney, the leading American linguist of his time, had to say about metaphor and other figures as early as 1875 :

A conspicuous branch of the department of figurative transfer, and one of indispensable importance in the history of language, is the application of terms having a physical, sensible meaning, to the designation of intellectual and moral conceptions and their relations. It is almost useless to attempt to illustrate this; the examples would come crowding in too numerously to be dealt with; ... In fact our whole mental and moral vocabulary has been gained precisely in this way; the etymologist feels that he has not finished tracing out the history of any one of its terms until he has hunted it back to the physical conception in which, by the general analogies of language, it must have had its origin. ... [T] here is no grander phenomenon than this in all language-history. (Whitney, 1875/1979, pp. 88-90)

To return to Lakoff (1987): "Comprehending experience via metaphor is one of the great imaginative triumphs of the human mind" (p. 303). Does this sound familiar, given the passage quoted above?

In sum, there is nothing wrong with "Objectivism", apart from the label itself, as pointed out by Haser (2005). So why did the notion provoke such a negative response, in 
the first place? A brief look at the recent history of linguistics and/or philosophy suggests a possible answer. After the initial triumphs of generative linguistic, there was an unforeseen problem:

\begin{abstract}
Transformationalists originally based their analysis on such unequivocally correct sentences as The man hit the ball and John found the boy studying in the library. Little by little, however, they have been driven to analysing more and more complex or outlandish sentences, ... with the result that it is increasingly difficult, and often impossible, to reach a general agreement concerning correctness, synonymy, ambiguity, etc of sentences under discussion (cf. Botha, 1973:178-185 for elaboration). ... This situation, which is rightly considered intolerable (Labov, 1972: 191-202), can be avoided easily enough, however. Where linguistic knowledge is unreliable, that is, where there are no absolutely binding rules of language, it is natural to take recourse to observation of actual speech and/or to psycholinguistic experimentation. ... It must be emphasized, however, that the unreliability of some intuitions by no means entails the unreliability of all intuitions. (Itkonen, 1978, pp. 152-153)
\end{abstract}

The emergence of different kinds of observational and/or experimental linguistics was, at least in part, a reaction to precisely this state of affairs. This was a welcome development. But there was also an over-reaction, expressed in the claim that intuition-based research had to be rejected in toto, based on the fallacious inference from "some" to "all".

Analogous developments have been taking place in philosophy. The Pap-type "analysis-by-entailment" is impeccable in itself, but it may occasionally appear artificial and/or restrictive. Dennett (2014) takes this question very seriously: "[O]ne's own intuitions are apt to be distorted by one's theoretical predilections. ... Philosophers have recently begun to appreciate this point, in the new enthusiasm for the so-called experimental philosophy" (p. 416). Actually, Pap (1958) has a better answer to solution: we just should refrain from jumping from "some" to "all". The following sections address some other alleged problems of philosophy and linguistics based on imagination, and offer solutions.

\title{
6. Believing to be able to imagine $X$ does not entail being able to imagine $X$
}

What can or cannot be imagined is not so straightforward. Wittgenstein (1958a, p. 111, $\$ 350)$ provides the following example: "You surely know what 'It is 5 o'clock here' means; so you also know what 'It's 5 o'clock on the sun' means. It means simply that it is just the same time there as it is here when it is 5 o'clock". In other words, we may think that we understand (= can imagine) something that, on reflection, we realize that we actually do not understand and cannot imagine. "For many mathematical proofs do lead us to say that we cannot imagine something which we believed we could imagine. ... They lead us to revise what counts as the domain of the imaginable" (p. 141, §517).

To keep things simple (e.g. to avoid unnecessary complications concerning the viability of time-measurements in different regions of the universe), Wittgenstein's original pair of examples was replaced in Itkonen (1983a, p. 120) by (21) vs. (22). To simplify things even more, these may in turn be replaced by (23) vs. (24).

(21) It is evening in London.

(22) It is evening on the sun.

(23) There is now a sunset in London.

(24) There is now a sunset on the sun. 
It is surely impossible to consistently imagine the situation that makes (24) true (assuming the universe to be as it is now). The notion of 'consistent imagination' may be clarified as follows:

\begin{abstract}
A moment's reflection was said to be enough to show that 'It is evening on the sun' is meaningless. The decisive question is now what this kind of 'reflection' means. I think it would be correct to say that it means realizing what it would be like to verify the sentence in question. However, the term 'verify' is often used in a very narrow and concrete sense, and therefore, to obviate possible misunderstandings, I prefer the following formulation: realizing that ' $\mathrm{p}$ ' is meaningful (or meaningless) means realizing that one is able (or unable) to tell a coherent and acceptable story about that which makes 'p' true. (Itkonen, 1983a, p. 120)
\end{abstract}

In short, imagination cannot be equated with the claim, or belief, that one can imagine something. Much argumentation in the philosophy of mind makes reference to "philosophical zombies" - creatures like you and me, but lacking any kind subjective experience. It is, however, far from clear that such a thing can be consistently imagined, as pointed out by Thompson (2007).

\title{
7. The limits of imagination
}

\subsection{Contradictions}

The precise content of the word imagination depends on the context. In connection with examples like (14), (17), and (20), it seems to designate something that is simply given. By contrast, a more dynamic interpretation is presupposed when imagination is called upon to invent a coherent and acceptable story (as distinguished from an incoherent and unacceptable one), as in connection with examples like (21) and (22). This might be called imagination in action. To be sure, it was implicitly exemplified already in connection with (15) and (18).

In conducting his philosophical analysis, Wittgenstein is constantly and explicitly making use of imagination. Apparently, he feels free to attempt imagining anything and to find out where this leads him. In other words, the limits of consistent imagination are constantly explored by means of imagination in action. This is the case, for instance, when he writes: "Orders are sometimes not obeyed. But what would it be like if no orders were ever obeyed? The concept 'order' would have lost its purpose" (1958a, p. 110, §345) or "One can imagine an animal angry, frightened, unhappy, happy, startled. But hopeful? And why not?" (p. 174). A more extensive example is the following:

\footnotetext{
Here is a possibility: I hear that someone is painting a picture 'Beethoven writing the ninth symphony'. I could easily imagine the kind of thing such a picture would show us. But suppose someone wanted to represent what Goethe would have looked like writing the ninth symphony? Here I could imagine nothing that would not be embarrassing and ridiculous. (ibid, p. 183)
}

In general, he states: "My aim is to teach you to pass from a piece of disguised nonsense to something that is patent nonsense" (p. 133, §464). And patent nonsense typically amounts to contradictions, as those expressed by (22) and (24). Still, it might be good to check one's (imaginary) point of departure every now and then. Mundle (1970) expresses the following caveat: "Wittgenstein prescribes ... that we should ... confine ourselves to describing, assembling reminders about, everyday uses of language ... But ... [in his work] we find few remarks that appear to be reminders about everyday language, and they are usually false" (p. 128). 
No doubt Wittgenstein's agenda is here conceived of too narrowly (which is largely due to some misleading formulations of his own). In any case, the following norm should be adhered to: In our flights of imagination, we are certainly free to go beyond everyday language and thinking. But if it is our deliberate purpose to describe everyday language as it is, then we do not have the right to imagine that it is different from what it is in fact. In this sense, then, Mundle's iconoclastic criticism is welcome.

Of course, Pap is bound to practice imagination in action as well. This is evident, when he asks: "Is it logically possible that a man should be entirely devoid of reasoning ability?' we ask in order to make clear to ourselves the meaning of 'man' ..." (1958, p. 422). This question presupposes that there is no clear-cut, black-or-white answer. That is, we are dealing with a gradual distinction. But does this not contradict Pap's basic assumption about the fundamental role of (non-gradual) necessity? Not at all, as repeated once more: "gradual/relative" and "non-gradual/absolute" are fully compatible, once they have been put into the proper perspective. Just consider this additional remark from the last page of Pap's magnum opus: "To him who does not grasp the sense of 'possible' in which the existence of immortal men is possible yet the existence of round squares not possible, no analytic philosophy can be taught" (p. 422). The distinction between immortal men and round squares, as conceived of by Pap, is an absolute one, even if the two types of entities are located on the same continuum.

In discussing the relation between mind and matter, Searle (1992, p. 32) offers another example of the difference between thinking that we can imagine, and actually being able to:
We think the following question must make sense: How is it possible for unintelligent bits of matter to produce intelligence? ... Unintelligent bits of matter can produce intelligence because of their organization.... [But] both the question and the answer are incoherent. ... [W] really haven't the faintest idea of what we are talking about.

Once again, it is asserted that we cannot, in the last resort, imagine something that we first thought we can. But in this case the issue is inflammatory, or loaded with "metaphysical passions", to such an extent that it may never be possible to reach a general consensus on whether it really does or does not involve a contradiction.

\subsection{Ontological puzzles}

It is notoriously impossible to imagine a contradictory entity such as a round square. But contradictions may also be less obvious. This raises the possibility of another (although related) type of unimaginability, namely the one related to ontology. The spectrum of the principal ontological "levels" will be reviewed here, arranged in the order from the least to the most palpable. These reflect Popper's (1979) taxonomy of the three "worlds", that have already been mentioned. ${ }^{11}$

\subsubsection{World-3}

In philosophy, Platonism refers to the Doctrine of Ideas (or Forms): "[Plato] has no doubt that the Ideas exist outside the human mind, ..." (Cairns, 1963, p. xix). More precisely, this

\footnotetext{
${ }^{11}$ In the name of historical accuracy, it needs to be added that Popper was anticipated by several thinkers. As pointed out by Johnson (1987, p. xxx): "Frege thought it necessary to identify three ontologically distinct realms: (i) the physical, consisting of physical objects...; (ii) the mental, containing what he called 'ideas', 'images', and other mental representations; and (iii) a realm of thought, consisting of objective senses $[=$ meanings $]$...”
} 
is "the doctrine that abstract objects (like numbers and sets of numbers) have an objective existence with properties that people can only discover, not invent" (Davis, 2000, p. 133). Platonist Ideas are supposed to be "eternal", in the sense of being beyond space and time. This may not sound too implausible as far as mathematical and logical entities are concerned, but it does sound outright outlandish when we speak of ordinary things:

\begin{abstract}
There are many couches and tables, ... But these utensils imply, I suppose, only two ideas or forms, one of a couch and one of a table. ...[T]he craftsman who produces either of them fixes his eyes on the idea or form, and so makes in the one case the couches and in the other the tables that we use, ... For surely no craftsman makes the idea itself. (Republic 596b-c)
\end{abstract}

This passage immediately reveals the basic quandary of Platonism. Because we are located in space and time just as couches and tables are, we are able to "fix our eyes" on them; but because Ideas (of a couch or of a table) are not located in space and time, it does not seem possible for us to "fix our eyes" on the latter. Surprisingly, Plato himself expressed this very criticism on a later occasion, in Parmenides. That he uses the older philosopher Parmenides as his mouthpiece, and not Socrates, as usual, does not invalidate this criticism. What follows is an exchange between the former and the latter:

\begin{abstract}
But, as you admit, we do not possess the forms themselves, nor can they exist in our world. - No. - And presumably the forms, just as they are in themselves, are known by the form of knowledge itself. - Yes. - The form which we do not possess. - True. Then, none of the forms is known by us, since we have no part in knowledge itself. (Parmenides 134b-c)
\end{abstract}

Russell (1946: Ch. 15) characterizes this passage as one of the most remarkable moments in the history of philosophical self-criticism. To be sure, Plato can hardly be said to have changed his mind concerning Ideas; but he apparently began to have some doubts. Why? Maybe he realized that he could not, after all, imagine how (spatio-)temporal beings can come into contact with non-temporal entities.

Thanks to Katz (1981), Platonism has become a respectable option within the metatheory of linguistics, especially as a way to avoid psychologism. But it is not the only option, as I have pointed out before:

\begin{abstract}
It would seem more correct to me, however, to let historical and social norms (of language), rather than 'eternal' Platonic entities, stand for the abstract objects analysed by grammatical theory... Katz explicitly claims that a human language is not a social, but a mathematical entity (pp. 7-8, 48). It is hard to see the justification for this claim, because language quite obviously differs from mathematical entities in being subject to diachronic, geographic, and social variation. (Itkonen, 1983b: 240-241)
\end{abstract}

It seems uncontroversial to claim that the ontological level of norms is easier to imagine than the level of Platonic Ideas. Still, it is undeniable that many people have been, and are, reluctant to accept the existence of norms, as is evident from their desire to reduce them to something non-normative, i.e. to something that is supposed to be ontologically more basic. For instance, it is rather customary to try to reduce norms (or rules) of language either to speaker intentions or to hearer beliefs (and/or expectations). On reflection, it is obvious, however, that intentions and beliefs are irrelevant if they are incorrect. Only correct intentions and beliefs matter, which means that normativity remains irreducible. It is notable that leading representatives of cognitive linguistics do not even realize the need for reduction, as pointed out by Rakova (2002, p. 240): “A theory of linguistic meaning has to accommodate the notion of normativity, which never makes its way into the experientialist claims [by Lakoff and Johnson]". 
Such an "anti-normative" position is arguably due to the prestige enjoyed by the natural sciences. The data of physics lack normativity; if linguistics is to qualify as a legitimate science, also linguistic data must lack normativity; linguistics is to qualify as a legitimate science; ergo, linguistic data must lack normativity. Needless to say, this argument is less than cogent: "There is no way of claiming a physical character for the study of [linguistic] phenomena, except by a thorough misapprehension of their nature, a perversion of their analogies with the facts of physical science" (Whitney, 1979/1875, p. $311)$.

It is quite understandable that there should be some unclarity concerning the relation between the Platonic and the Social interpretation of World-3, as shown by the following response to Frege's "realm of thought":

The doctrine that there is a real sense [= meaning] of a sign, distinct from any individual's idea of it, which somehow society is able to possess as public property and to pass down to the next generation, is likely to perplex any psychologist. How can the sense of a sign be the property of many and passed from generation to generation without entering the mind? And yet, if it does enter the mind - and Frege and his successors certainly assumed that meanings did enter the mind - then in what way is it different from an idea? (Johnson-Laird, 1983, pp. 183-184)

Johnson-Laird's question has been answered by Edgley, von Wright, and many others: Meanings are different from ideas thanks to their dual, subjective-cum-objective nature, which they share with (correct) beliefs and belief-relations, such as entailments (see Section 7.2.4). Of course, a distinction has to be made between World-3 and World-2. Yet, a misleading impression may be created by treating them separately, as is done here, because they constitute a natural unity. As an alternative to the Katz-type Platonism, this unity can be formulated in the following way:

We as individuals construct sentences or proofs in accordance with norms entertained by us as a community. On this view we have to posit a dichotomy between (social) norms and (psychological) internalizations-of-norms. (Itkonen, 1983b, p. 243)

\subsubsection{World-2}

"The actual ontology of mental states is a first-person ontology" (Searle, 1992, p. 16). This is correct, except that what we have is, more precisely, a first-person-singular ontology. By contrast, the ontology of norms is a first-person-plural ontology. As shown by Wittgenstein's private-language argument: there can be no exclusively first-person-singular language. The "plural" aspect is indeed true of the ontology of norms, not of their epistemology: a norm may not be experienced as being shared by many, but it is, and must be, shared by many.

The mental World-2 must be interdependent with the social/normative World-3. Still, for analytical purposes, it makes sense to assume that the mental world, qua mental, is ontologically homogeneous. But just as clearly, this world is epistemologically heterogeneous, in the sense that beliefs and goals, qua World-2 entities, can be either conscious or unconscious. This distinction is notoriously a relative one, because unconscious beliefs and goals can become conscious (and vice versa). Rational explanation is based on the idea that an action A is explained as being caused by a "volitional-epistemic complex": because the agent has both the goal X and the belief that A is the means to achieve $\mathrm{X}, \mathrm{s} /$ he will (attempt) to do $\mathrm{A}$; in short: $(G \& B) \rightarrow A$. In pragmatics, $\mathrm{G} \& \mathrm{~B}$ is typically conscious whereas in diachronic and/or typological linguistics $\mathrm{G} \& \mathrm{~B}$ is typically unconscious. The non-nomic character of rational explanation makes it radically different from explanations employed in astronomy or physics (Itkonen, 1983a, 2013). 
Dennett (1991) disagrees with the above: "We can ... account for every mental phenomenon using the same physical principles, laws, and raw materials that suffice to explain radioactivity, continental drift, photosynthesis ..." (p. 33); "The challenge is to construct a theory of mental events, using the data that the scientific method permits" ( $\mathrm{p}$. 71). This is the stance of materialism, understood as all-out physicalism. As Dennett sees it, the opposite of materialism is dualism, or the doctrine that, in addition to "physical stuff", there is also another kind of substance, namely "mind stuff". According to him, dualism is confronted with an insoluble problem: "How can mind stuff both elude all physical measurement and [yet] control the body?" (p. 35). Hence materialism seems to be the only viable option: "I adopt the apparently dogmatic rule that dualism is to be avoided at all costs" (p. 37).

It is not too difficult to see that Dennett presents us with a false dichotomy. The true opposite of materialism is not dualism but non-materialism (in the sense of "less-thanabsolute materialism"). Dennett himself provides several arguments for non-materialism. For instance, he accepts the existence of "[semantic] similarities ... that are not describable in the terms appropriate to the syntactical or textual (let alone physical) description ..." (p. 80). But, by his standards, whatever is not physical, does not exist. And yet, these presumably non-existent (= semantic) entities are all-important in the present context.

To give another example: "The power of the [algorithmic] procedure is due to its logical structure, not the causal powers of the materials used in the instantiation, ..." (Dennett, 2014, p. 141; the second emphasis added). Here "causal" equals "physical"; and a stark conflict is claimed to exist between "logical" and "causal/physical". But, by Dennett's own standards, this is impossible because there is nothing over and above what is physical: there is no "logical power". The upshot is that absolute materialism/physicalism is just incoherent. Searle (1992) agrees with this argument: "Semantics is not intrinsic to syntax ... [and] syntax is not intrinsic to physics" (p. 210). Clearly, logic is even farther removed from physics than is semantics.

Dennett (1991) accepts the existence of "a rational agent who harbors beliefs and desires and other mental states that exhibit intentionality or 'aboutness', and whose actions can be explained (or predicted) on the basis of the content of these states" (p. 76). Prima facie, Dennett just seems to be formulating the notion of rational explanation, but this is not the case. Predictions must be based on nomicity (i.e. lawlikeness) in the data, but the actions of rational agents cannot be predicted, as rational explanation offers only post hoc explanations. This is self-evident in the domain of pragmatics: it borders on absurdity to claim that we can predict what, exactly, different people are going to say, and when. But the same is also true (even if less obviously) of other subdomains of linguistics, for instance, of diachronic linguistics: "The laws of general-historical phonetics or morphology do not suffice to explain a single fact ... we are not able to predict a single future development ..." (Meillet, 1921, p. 16; for discussion, cf. Itkonen, 1984, 2011).

Notice also that genuine Dennett-type predictions about intentional actions cannot be made unless the content of beliefs and desires have first been redefined in purely physical terms. Needless to say, no one has any idea how this could be done. Hence, materialism represents no threat to either World-3 or World-2. Rational explanation remains a sui generis type of explanation, incompatible with materialism and compatible with nonmaterialism (i.e. World-3 and World-2).

As pointed out earlier, Dennett (2014) often attributes "failure of imagination" to his opponents (as when they claim to be unable to imagine, or conceive of, conscious robots). But it could also be argued, inversely, that clinging to all-out physicalism testifies to failure of imagination. In the present context, the important thing is that we are all the time dealing with the limits of imagination, either our own or somebody else's. 


\subsubsection{World-1}

Throughout his career, Einstein made a clear distinction between the mathematics used by physicists and the (physical) reality they ultimately try to capture. First of all, he was convinced that the (special) theory of relativity describes physical reality such as it is: "For [Einstein's] predecessors, the Lorentz transformation was merely a useful tool for linking objects in relative motion; for Einstein it was not a mathematical tool so much as a revelation about the nature itself" (Clark, 1973, p. 120).

But Einstein was equally convinced that the same is not true of quantum mechanics. In 1931 he claimed its basic shortcoming to be that it "makes no claim to describe physical reality itself, but only the probabilities of the occurrence of a physical reality that we view" (Isaacson, 2007, p. 349). In 1927, he declared that "I do not approve of the purely statistical method of thinking on which the new theories are based" (op. cit., p. 345). Therefore, it should be the goal of physics, "to restore union between physical reality and the profoundest characteristic of Newton's teaching - strict causality" (p. 333). He repeated in 1952 that, according to quantum theory "laws don't apply to things, but only to what observation informs us about things ... Now, I can't accept that" (op. cit, p. 635, n. 24). Elsewhere as well, he saw a gap, or even a chasm, between mathematical description and physical reality. Karl Schwarzschild pointed out to him in 1916 that, as predicted by the theory of relativity, a massive star could collapse under its own gravitational pull, but Einstein responded in 1939 by writing an article intended to provide "a clear understanding as to why these 'Schwarzschild singularities' do not exist in physical reality" (p. 251; emphasis added). Today, these entities are known as black holes, and their existence is taken for granted.

This is the crucial question: Why did Einstein deny the physical reality of probabilistic quantum waves, black holes, etc? The simple answer is that it was something he was unable to imagine. The significance of this answer becomes evident when we remember that, by all accounts, Einstein had an exceptionally fertile imagination, as demonstrated by his numerous thought experiments; for instance: "His quest began in 1895, when as a 16-year old he imagined what it would be like to ride alongside a light beam" (p. 3; emphasis added). The lesson is obvious: the ontological reality of atoms, genes, and black holes has been first denied and then accepted; and there is no reason to think that the same pattern will not continue. Lévi-Strauss (1991) summarizes the situation as follows:

Chez nous, les connaissances positives débordent tellement les pouvoirs de l'imagination que celle-ci, incapable d'appréhender le monde dont on lui révèle l'existence, a pour le seule ressource de se retourner vers le mythe. Autrement dit, entre le savant qui accède par le calcul à une réalité inimaginable, et le public avide de saisir quelque chose de cette réalité dont l'évidence mathématique dément toutes les données de l'intuition sensible, la pensée mythique redevient un intercesseur, seul moyen pour les physiciens de communiquer avec les non-physiciens. (p. 11; emphasis added $)^{12}$

Two distinct claims are made here. On the one hand, at least for ordinary mortals, some of the results of modern science are beyond the powers of imagination. On the other hand, the only way to make them somehow comprehensible to the lay audience, even if very

\footnotetext{
12 "In us, positive knowledge so overwhelms the powers of the imagination that the latter, unable to apprehend the world whose existence the former has revealed, has for the only resource to turn to myth. In other words, between the scientist who accesses by calculation an unimaginable reality, and the public eager to grasp something of this reality whose mathematical evidence belies all the data of sensible intuition, mythical thought becomes again an intercessor, the only way for physicists to communicate with non-physicists. (my translation).
} 
indirectly, is to return to mythological thinking. The first claim is uncontroversial while the second is not. It is a simple fact that other strategies have been used as well, as I have pointed out before:

\begin{abstract}
Modern physics, with its non-Euclidean space and probability waves, shows, however, that a theory may be familiar in a technical sense and yet lack any pictorial model [capable of being clearly imagined]. ... This creates an interesting tension (if not an outright contradiction). Popular books on modern physics, like Zukav (1980), repeat the thesis of non-pictoriality and yet make constant use of pictures to clarify the points they make. (Itkonen, 2005, p. 193)
\end{abstract}

\title{
7.2.4 Interconnecting the three "Worlds"
}

The following citation of Edgley (1978/1965, p. 24) expresses one of the most important truths of psychology and linguistics with exceptional clarity:

Every belief must have both a history and a logic; for they are concerned each with a different element of the belief. "Believe" is a psychological verb, and the history of a belief is therefore a psychological story; what is believed, a proposition, is a logical entity, having only logical properties and relations, which are non-temporal.

von Wright (1984, p. 14) confirms this:

Primarily, truth and falsity belong to the content of beliefs, judgments, and statements, i.e. to that which is believed, judged, or stated, ... [as opposed to] the phenomena of belief, judgment, and statement which are tied to persons or subjects. ... It is for speaking about those "that which" things that philosophers may find it useful to employ the term proposition.

It is the basic thesis of Itkonen (1983a) that while human actions cannot be (causally) explained without recourse to rationality, this can be done only by fully endorsing its "Janus-like character" (ibid, pp. 177-181). What this weird-sounding expression designates is just the duality of psychological and objective addressed by Edgley and von Wright. To combine Edgley's and Popper's terminologies, the (psychological) history of a belief belongs to World-2 whereas its logic belongs to World-3. Entailments (i.e. necessary, deductive relations) can hold only between beliefs qua "inhabitants" of World-3. This is how Davidson (1975), for his part, formulates the underlying duality:

If someone is glad that, or notices that, or remembers that, the gun is loaded, then he must believe [= World-2] that the gun is loaded. Even to wonder whether the gun is loaded ... requires [= entails] the belief $[=$ World-3], for example, that a gun is a weapon, that it is a more or less enduring physical object, and so on. There are good reasons for not insisting on any particular list of beliefs [= World-3] that are needed if a creature is to wonder whether the gun is loaded [i.e. that are entailed by the belief that the gun may be loaded]. Nevertheless, it is necessary that there be endless interlocking beliefs. (pp. 7-8; emphasis added)

Much of the lack of clarity that prevails in the philosophy of linguistics and/or psychology results from an inclination to conceptualize all these facts within a single homogeneous (ultimately psychological) framework. Some of the attendant difficulties become apparent even in Davidson's quotation. He claims that if someone is glad that the gun is loaded, then he must believe that the gun is loaded, that it is a physical object, and so on. But if this 
someone happens to be a moron, this is far from self-evident. ${ }^{13}$ We must repeat that no absolute necessity exists in the mental World-2. It exists only in the normative World-3, with the consequence that "must" becomes synonymous with "ought". In other words, this is what Davidson should have said: "If someone is glad that the gun is loaded, then assuming $\mathrm{s} / \mathrm{he}$ is a rational person $-\mathrm{s} /$ he must believe that ...".

On the primary interpretation, what is true of to believe is true of to imagine as well. The (intersubjective) World-3 character of what is believed or imagined is evident from the following chain of definitions: to know the meaning of $p=$ to be able to verify $p=$ to be able to tell a coherent and (generally) acceptable story about $p$, as pointed out in Section 6 .

The analogy between believing and imagining has been emphasized here, insofar as the "history/logic" duality is concerned. On the other hand, there are obvious disanalogies as well. First, believing is always involuntary whereas imagining is often voluntary: in the "introspective experiments" of Kroy (1976), in particular, participants are confronted with the task of finding out what they can or cannot imagine. Second, the question of truth vs. falsity is all-important with respect to beliefs but largely irrelevant with respect to what is imagined. ${ }^{14}$

The nature of dreams is apt to throw additional light on this issue. This is how Kneale (1970) describes what she calls "the traditional account of dreaming":

\begin{abstract}
When we dream, we are in sleep accepting as true certain propositions which are, for the most part, false. These are expressed in, or accompanied by, imagery of various sorts and they may also occasion emotions. The contents of beliefs ... are false but the believing or imagining are themselves real and so are the emotions they arouse ( $\mathrm{p}$. 238).
\end{abstract}

This scenario emphasizes the similarity between being awake and dreaming. This has always been used, by Socrates among others, to plead for scepticism, along the following line of argument: (i) When I am dreaming, I (erroneously) think I am awake. Therefore, although I now think I am awake, perhaps I am dreaming. (ii) Most of what I believe when I am dreaming is false. Therefore, most of what I now believe is perhaps false (because I may be dreaming).

Kneale (1970, pp. 238-241) points out that this traditional argument is fallacious insofar as, by simplifying the nature of dreams, it comes to exaggerate the similarity between being awake and dreaming: "all dreaming is believing". Instead, Kneale (p. 243) suggests another option: "Do we believe when we dream or do we merely imagine?" (given that "in imagining we do not believe the propositions we entertain"). Her "unexciting" answer is 'both - and'; but, in any case, it departs from the traditional view. In the present context, the important thing is the overlapping tripartite taxonomy "believing - imagining dreaming", where the last two members are prime examples of non-observation.

\title{
8. Historical notes on imagination
}

Before concluding, let us add some historical background for the preceding discussion. For Aristotle (d. 322 BC), the soul has two sources of certainty, either concrete (= senseperception) or abstract (= knowledge/intelligence), and imagination, qua the primary source of error, is located between these two. A few excerpts from De Anima 427b-429a show this:

\footnotetext{
13 "It is quite significant that idiots are not really considered to be 'subjects"” (Kroy, 1976, p. 146); still, notice the range of uncertainty expressed by "not really".

${ }^{14}$ See Appendix A for a discussion of the work of Kroy (1976).
} 
$[\mathrm{P}]$ erception of the special objects of sense is always free from error, ... [S]ensations are always true, imaginations are for the most part false. ... Neither is imagination any of the things that are never in error: e.g. knowledge and intelligence; for imagination may be false. ... [I]t is possible to think falsely as well as truly ... Thinking is different from perceiving and is held to be in part imagination, in part judgement. ... And because imaginations ... resemble sensations, animals in their actions are largely guided by them, some (i.e. the brutes) because of the non-existence in them of mind, others (i.e. men) because of the temporary eclipse in them of mind by feeling or disease or sleep.

As expounded in De Anima 412a-414a, Aristotle conceptualizes a tool as consisting of matter (= potentiality) and of two types of actuality, the first (= function, or "the power in the tool") and the second (= actual use). The body-soul relationship is in turn conceptualized on the analogy of a tool: the body exemplifies matter/potentiality while the soul exemplifies the two types of actuality; for instance: the eye-ball $\rightarrow$ the ability to see $\rightarrow$ actual seeing. "From this it indubitably follows that the soul is inseparable from its body, ..." All this in turn follows from Aristotle overall metaphysics: "[E]verything that Nature makes is means to an end. For just as human creations are products of art, so living objects are manifestly the products of an analogous cause or principle, ..." (De Partibus Animalium 641b, 10).

René Descartes (1596-1650) based his metaphysics on the dichotomy between res extensa and res cogitans. As far as human beings are concerned, this is the dichotomy between body (corps) and soul (ame). Correspondingly, the superordinate notion of thinking (pensée) is divided into imagination (imagination), which emanates from the body, and reason (raison), which emanates from the soul. It goes without saying that, in this scenario, imagination is not only separated from but also inferior to reason (Ricken, 1988). This position is bolstered, more concretely, by the following example at the beginning of Meditation VI:

And to render this quite clear, I remark, in the first place, the difference that subsists between imagination and pure intellection [or conception]. For example, when I imagine a triangle I not only conceive (intellego) that it is a figure comprehended by three lines, but at the same time also I look upon (intueor) these three lines as present by the power and internal application of my mind (acie mentis), and this is what I call imagining. But if I desire to think of a chiliagon, I indeed rightly conceive that it is a figure composed of a thousand sides, as easily as I conceive that a triangle is a figure composed of only three sides; but I cannot imagine the thousand sides of a chiliagon as I do the three sides of a triangle, nor, so to speak, view them as present" (Descartes, 1974/1960: 161-162; parenthetical additions in the English translation).

As noted by Williams (1978: 231), "this is another variant of the sort of point that Descartes has repeatedly made about the difference between the imagination and the intellect". Still, the issue is slightly more complicated: "In the earlier work, the Regulae, he takes a more positive view of the usefulness of images to conceptual thought" (ibidem). ${ }^{15}$

\footnotetext{
${ }^{15}$ The soul vs. body separation, which is the essence of Cartesian psychology, was anticipated in Greek philosophy, and its basic weakness was duly noted by Aristotle: "[This view] involves the following absurdity: it joins the soul to a body, or places it in a body, without adding any specification of the reason of their union, or of the bodily conditions required for it. Yet such explanation can scarcely be omitted; for some community of nature is presupposed by the fact that one acts and the other is acted upon, ...; interaction always implies a special nature in the two interagents. All, however, that these thinkers do is to describe the special characteristics of the soul; they do not try to determine anything about the body which is to contain it, as if it were possible ... that any soul could be clothed upon with any body,... It is as absurd as to say that the art of
} 
Blaise Pascal (1623-1650) elaborated on the Cartesian dichotomy. As he saw it, rhetoric and eloquence appeal to imagination whereas logic is based on reason:

Imagination. - C'est partie dominante dans l'homme, cette maîtresse d'erreur et de faussété, et d'autant plus fourbe qu'elle ne l'est pas toujours; ... Mais étant le plus souvent fausse, elle ne donne aucune marque de sa qualité, marquant du même caractère le vrai et le faux. ... Cette superbe puissance, ennemie de la raison ... a établi dans l'homme une seconde nature. (Pascal, 1972/c. 1658, pp. 41-42; emphasis added). ${ }^{16}$

Still, Pascal's position is not entirely black-and-white. On the one hand, imagination has its pedagogical use. On the other, people are in general unable to put reason into practice. Thus, Pascal agrees with Aristotle that intelligence and sense-perception are the "two principles of truth", but he is much more sceptical than Aristotle about their practical value.

Any sharp divide between imagination and reason was rejected by, for instance, Hobbes and Gassendi in their argument against Descartes. Instead, they postulate some sort of "ascent" from the former to the latter (cf. Johnson, 1987, pp. 145-147; Ricken, 1988). For my part I have tried to show in this article that, in reality, part of the imagination is identical with the Descartes-type reason.

\section{Conclusions}

We began by presenting Thompson and Hopper's (2001) claims about the imagination being a "vulnerable" methodology. What this article has shown is that they, and most other sceptics concerning imagination, are mistaken. Properly understood, imagination is not vulnerable. As far as (the study of) meaning is concerned, it is, on the contrary, extremely robust. Let us recall Pap's (1958) remark about imaginability: "there is no alternative to it" (p. 218).

Imagination is at the core of rationality as a normative notion: one ought to act rationally; or, even more explicitly, it is right to act rationally. Philosophy teaches the same lesson, in a twofold sense. First, unlike psychology, philosophy does not investigate our de facto way of thinking: "The problem for epistemology is not "Why do I believe this or that?' but 'Why should I believe this or that?"' (Russell, 1962/1940, p. 14). Second, philosophy should not be satisfied to describe existing norms of correct or rational thinking. It is the traditional task of philosophy to teach us to think better, which arguably amounts to creating or recommending new norms of (rational) thinking. Still, this is a nebulous area, so let us be more precise. Perhaps it is the case that our life is dominated by "unconscious imagination" with its roots in unspeakable destructive urges. In this article, however, several reasons have been given why conscious and voluntary imagination ought to play a more prominent role in linguistics, philosophy and logic.

\section{Appendix A. "The common-sense theory of imagination" of Kroy (1976)}

Kroy (1976) provides a strong defence of the thesis that formal logic is ultimately based on imagination. In epistemic logic, possible-worlds semantics has been massively used to

carpentry could embody itself in flutes; each art must use its tool, each soul its body" (De Anima $407 b, 15-25$; the second emphasis added).

16 "Imagination. It is a dominant part in man, that mistress of error and falseness, and all the more deceitful as she is not always so; But, being most often false, it gives no mark of its quality, marking with the same character the true and the false. ... This superb power, enemy of reason ... has established in man a second nature." (my translation) 
describe such propositional attitudes and/or mental acts as belief, knowledge, perception, remembering, etc. Kroy (1976) goes one step farther. His general argument contains the following steps:

(i) "The possible-worlds semantics ... will be interpreted by making 'possible worlds' psychological constructs" (p. 10). "The formal rules defining 'possible worlds' ... can be reinterpreted as rules which the imagination applies in constructing possible worlds" (p. 11). "We will transform modal logic from a mathematical discipline into an empirical theory of mental functioning. ... This theory is empirical in the same way a theory of linguistic competence, i.e. a grammar, is" (p. 99).

(ii) "We intend to extract, on reflecting on these usages [i.e. those of words like imagination, to imagine, and imaginable $], . .$. the common-sense theory of imagination" (p. 101). "Fiction is a rather large constituent of our culture. ... How did the writer (author, story teller) know to write this story in this particular manner? He ... did not perceive those things happening. He 'imagined' them. They are "products of his imagination'” (pp. 103-104).

(iii) "Whatever the imagination of the story-teller can produce, the imagination of any of his 'clients' can reproduce. ... Stories are sequences of propositions. If we need imagination to understand them, why is it not imagination which is required to understand each of these propositions separately?" (p. 106). "The imagination ... produces representations of possible worlds in which the propositions in question are true" (p. 108).

(iv) "To understand a proposition is to imagine a situation in which this proposition is true. What, however, about argumentation? ... Validity of the argument is precisely that: the truth of its premises guarantees the truth of its conclusion in all 'possible worlds'. Thus evaluations of validity of arguments depend on the imagination, since stories are essentially involved. The definition of validity in terms of 'all possible worlds' is intimately connected with 'all situations we could possibly imagine'. This connection is closely related with the recurrent identification of logically false statements as 'inconceivable' or 'unimaginable"' (pp. 112-113).

(v) Next, the results achieved in connection with story-telling, propositionunderstanding, and validity-checking are extended to phantasies and plans (pp. 115-122). On the whole, this turns out to be an ambitious agenda for the human sciences, given that, in the prototypical case, to perform an action presupposes planning why and how to act; and it is precisely the capacity to act which distinguishes human beings from physical things.

(vi) Finally, the "empirical" (or "phenomenological") adequacy of this theory of imagination is meant to be tested by a set of "introspective experiments", where test persons have to answer the following questions (pp. 138-154): "Can you imagine A?", "Can you imagine B without imagining C?", "If you imagine D, can you also extend the imagined situation to include E?"

It goes without saying that, prima facie, Kroy (1976) validates one version of the thesis of the present paper, which is summarized as the identity of "possible (worlds)" with "imaginable (worlds)". Nevertheless, it is just too simple to take modal (possible-worlds) logic and to "reinterpret" it, telle quelle, as an empirical psychological theory. There are well-known arguments against this type of straightforward psychologism, summarized e.g. by Bergman (1957, pp. 30-31):

Our minds are not so constituted that when we grasp what a sentence or a group of sentences $[=$ premises] says we also know what they imply [= conclusion]. To know that, we must 'reason' deductively. ... Take Euclidian geometry, with which we are 
all familiar. Its axioms are few and simple; we all know them after a fashion. Its theorems are many, some very complicated. Yet all theorems, those already 'discovered' as well as those nobody has yet thought of, are deductive consequences of the axioms".

The upshot is that deductive reasoning cannot just result from our psychological constitution if the former must be achieved by overcoming (and hence, in a sense, denying) the latter. Now, Kroy is knowledgeable enough not to endorse the traditional version of psychologism: "No past arguments (such as Husserl's [1913]) are at all relevant to this version of psychologism which we maintain, simply because we do not claim that logic is valid for psychological reasons" (p. 114). But it remains crucially unclear how to reinterpret deductive logic "not valid for psychological reasons" as an "empirical theory of mental [= psychological] functioning".

To be sure, Kroy is not totally without assistance: "The modern impetus for mentalism was first given in the works of Chomsky ... (p. 100). "The formal theory of the imagination presented thus far is methodologically analogous to a Chomskyan grammar" (p. 131). Kroy is perfectly right about this analogy, but, on reflection, it only strengthens my point, because Chomsky-type "mentalism" imitates deductive (= axiomatic) logic and is therefore incompatible with genuine psychology:

The [Chomskyan] 'ideal speaker' possesses no properties over and above those belonging to an axiomatic system; in fact, the two are identical (Itkonen, 1976, p. 214).

It is obvious that transformational grammar, with its unrealistic notion of competence, is not a psychologically real theory: the competence of the 'ideal speaker' is a 'mental grammar' but - as we just saw - this grammar is an imitation of axiomatic systems, which have been constructed for the description of artificial languages (p. 215).

I do not wish to deny that there is some ingenuity in his attempt to combine two dissimilar and partly defective traditions [i.e. mentalism vs. modal logic] into one nondefective whole. Yet it is by now easy to see that this strategy cannot work, simply because the research interests of the logician and those of the psychologist are too different. In fact, Johnson-Laird (1982, p. 33) convincingly argues for the psychological non-reality of possible-worlds semantics (Itkonen, 1983a, p. 305).

In sum, Kroy's (1976) overall argument proves to be less than successful. On the other hand, as indicated above, he seems to achieve the more limited goal of formulating a "common-sense theory of imagination", or at least an important fragment of such a theory.

\section{Appendix B. The authentic mind: Conscious or unconscious?}

Let us, rather presumptuously, consider the human mind as it has been conceived of within the Western tradition during the last 2,500 years. It is generally agreed that, starting with antiquity, the emphasis was first on the conscious aspect (or "layer") of the mind. This emphasis increased during the Classical Age and culminated in the Enlightenment faith in the powers of "Reason". The received view also agrees that, around 1900, Freud (anticipated by thinkers like Schopenhauer) introduced the era of the Unconscious, an era which still continues today.

The history of psychology exhibits, on a smaller scale, the same bipartite pattern: the method of conscious introspection was followed by the experimental method, i.e. a method concentrating on observable behaviour prompted by the unconscious mind (-cumenvironment). The "pre-modern" stage of psychology has been characterized as follows: 
This [early] psychology was not based on any systematic observation other than the writer's introspections of his own states of mind, ... and so psychology had the special task of describing sensations and ideas as they appear to conscious or sentient human beings. (Thomson, 1968, p. 19-20)

Around the beginning of the $20^{\text {th }}$ century, however, there was a turning point, with the following outcome:

Consciousness, as the field for investigation, description, analysis, and measurement, provides no data for important aspects of behaviour. ... Introspection - the essential instrument of psychological research - ...was revealed as less useful than had been uncritically assumed for centuries. (ibid, p. 87)

As for linguistics, the division of labour seems clear enough. Both in the East and in the West, synchronic-grammatical description, also known as "autonomous linguistics" (AL), has of necessity been based on conscious intuition about (exemplifications of the concept correct sentence in L (Itkonen, 1991, 2000). While presupposing the existence of one or another type of AL, both psycholinguistics and sociolinguistics (which emerged much later) deal with unconscious linguistic behaviour insofar as they make use either of the experimental method or of the observational-statistical method (Itkonen, 1980, 2002, Pajunen \& Itkonen 2019). The role of consciousness in the context of linguistic description was addressed in the 15/6 issue of Journal of Consciousness Studies (Zlatev, 2008b, 2008c; Itkonen, 2008b).

In outline, I still accept this picture. But it also needs to be nuanced somewhat differently, due to the argument of this article. While "imagination", of course, covers a huge area, we have concentrated here on that type of imagination that is not only conscious but also voluntary, and is directed at performing intellectual tasks. As far as I can see, it constitutes the essence of intellectual life.

Two lines of thinking, however, converge to argue the opposite view. On the one hand, experimentation, qua concern with the unconscious, is supposed to represent the "scientific" approach to the mind. On the other hand, the Freudian revolution is supposed to have shown that consciousness, dominated as it is by dark and ferocious impulses bursting out of the unconscious, represents the non-authentic and therefore secondary ("superficial") layer of the mind. This is the thrust of Kahneman (2011) argument that "fast" thinking is authentic whereas "slow" thinking is unauthentic.

For my part, I remain unconvinced. We certainly know that consciousness exists. But how, exactly, do we know this? The standard answer is that it is just given in everybody's immediate experience; for practical purposes, this is indeed quite enough. But it would be more satisfying, from the intellectual point of view, to have not just a "feeling" about $\mathrm{X}$ being the case but an argument that proves $\mathrm{X}$ to be the case.

Consider the following analogy. The existence of norms is supported by everybody's (subjective) experience (or "feeling") of correct vs. incorrect actions. But it is also possible to construct arguments that prove the existence of (intersubjective) normativity. First, there is Wittgenstein's private-language argument, which is, ultimately, a type of reductio ad absurdum: if there are no intersubjective norms, no one (knows that $\mathrm{s} / \mathrm{he}$ ) is mistaken, which is absurd. Second, a sentence that describes an empirical regularity is falsified by a counter-example whereas a sentence that describes a (simple, well-established) norm is falsified neither by a correct action (because it conforms to the norm) nor by an incorrect action (because it deviates from the norm), which means that normativity does exist as a sui generis phenomenon, distinct from empirical regularities (Itkonen 2019). 
Many different arguments can be, and have been, advanced to prove the existence of consciousness. But it is always a good idea to begin at the beginning. This is what Aristotle has to say:

\begin{abstract}
Since we also discriminate white from sweet, and indeed any sensible quality from every other, with what do we perceive that they are different? ... Therefore discrimination between white and sweet cannot be effected by two agencies which remain separate; both the qualities must be present to something that is one and single. ... What says that two things are different must be one; ... Therefore what asserts this difference must be self-identical, and as what asserts, so also what thinks or perceives. (De Anima 426b, 10-20)
\end{abstract}

What is, then, this "one and single"? It must be a consciousness: any given consciousness, that unifies various perceptions, memories, imaginations, etc. Importantly, this unifying capacity also applies, self-reflexively, to consciousness itself: "we must somewhere assume a sense which is aware of itself" (op. cit., 425b, 15-20); "the mind too is then able to think itself" $(429 b, 5)$; "mind is itself thinkable in exactly the same way as its objects are" (430a, $5)$.

\title{
Acknowledgments
}

I would like to thank two anonymous reviewers, as well as the editor of the journal, for the competent job they have done. The corrections they suggested were eminently justified.

\section{References}

Aristotle (1941). The basic works of Aristotle. Edited and with an introduction by R. McKeon. New York: Random House.

Bergman, G. (1957). Philosophy of science. Madison: The University of Wisconsin Press.

Botha, R. (1973). The justification of linguistic hypotheses. The Hague: Mouton.

Cairns, H. (1963). Introduction. Plato: Collected dialogues (pp. xiii-xxv). Princeton: Princeton University Press.

Chomsky, N. (1957). Syntactic structures. The Hague: Mouton.

Clark, R. W. (1973). Einstein: Life and times. New York: World Publishing Company.

Cruse, A. (2000). Meaning in language. Oxford: Oxford University Press.

Davidson, D. (1975). Thought and talk. In S. Guttenplan (Ed.), Mind and language (pp. 623). Oxford: Clarendon Press.

Davis, M. (2000). Engines of logic: Mathematicians and the origin of the computer. New York: Norton.

Dennett, D. C. (1991). Consciousness explained. Harmondsworth: Penguin Books.

Dennett, D.C. (2014). Intuition pumps and other tools for thinking. Harmondsworth: Penguin Books.

Descartes, R. (1974/1641). Meditations on the first philosophy (translated by J. Veitch). In The rationalists (pp. 99-175). Garden City, NY: Doubleday \& Company.

Edgley, R. (1970). Innate ideas. In Knowledge and necessity: Royal Institute of Philosophy Lectures, Vol. 3 (pp. 1-33). London: Macmillan.

Edgley, R. (1978/1965). Practical reason. In J. Raz (Ed.), Practical reasoning (pp. 18-32). Oxford: Oxford University Press.

Gettier, E. L. (1967/1963). Is justified true belief knowledge? In A.P. Griffiths: Knowledge and belief (pp. 144-146). Oxford: Oxford University Press. 
Haser, V. (2005). Metaphor, metonymy, and experientialist philosophy: Challenging cognitive semantics. Berlin: Mouton de Gruyer.

Isaacson, W. (2007). Einstein: His life and universe. New York: Simon Schuster.

Itkonen, E. (1974). Linguistics and metascience. Studia Philosophica Turkuensia II.

Itkonen, E. (1975). Concerning the relationship between linguistics and logic. Distributed by the Indiana University Linguistics Club.

Itkonen, E. (1976). The use and misuse of the principle of axiomatics in linguistics. Lingua $38,3 / 4,185-220$.

Itkonen, E. (1978). Grammatical theory and metascience. Amsterdam: Benjamins.

Itkonen, E. (1980). Qualitative vs. quantitative analysis in linguistics. In T.A. Perry (Ed.), Evidence and argumentation in linguistics (pp. 334-366). Berlin: De Gruyter.

Itkonen, E. (1983a). Causality in linguistic theory. London: Croom Helm.

Itkonen, E. (1983b). Review of Katz (1981). Lingua 60, 238-244.

Itkonen, E. (1984). On the 'rationalist' conception of linguistic change. Diachronica I/2, 203-216.

Itkonen, E. (1991). Universal history of linguistics: India, China, Arabia, Europe. Amsterdam: Benjamins.

Itkonen, E. (2000). Tolkaappiyam: The basic work of ancient Tamil language and culture. SKY Journal of Linguistics 13, 75-99.

Itkonen, E. (2002). Linguistics as a system of distinct types of ontology-cumepistemology. In P. Gärdenfors et al. (Eds.), In the scope of logic, methodology and philosophy of science: Volume two of the $11^{\text {th }}$ international congress of logic, methodology and philosophy of science, Cracow, August 1999 (pp. 431-444). Dordrecht: Kluwer.

Itkonen, E. (2003). What is language? A study in the philosophy of linguistics. University of Turku: Publications in General Linguistics 8.

Itkonen, E. (2005). Analogy as structure and process: Approaches in linguistics, cognitive psychology, and philosophy of science. Amsterdam: Benjamins.

Itkonen, E. (2008a). The central role of normativity in language and linguistics. In J. Zlatev et al. (Eds.), The shared mind: Perspectives on intersubjectivity (pp. 279305). Amsterdam: Benjamins.

Itkonen, E. (2008b). Concerning the role of consciousness in linguistics. Journal of Consciousness Studies 15/6, 15-33.

Itkonen, E. (2011). On Coseriu's legacy. Energeia III: 1-29. [Reprinted 2011 in Papers on typological linguistics (pp. 191-227). University of Turku: Publications in General Linguistics 15].

Itkonen, E. (2013). Functional explanation and its uses. In S.T. Bischoff \& C. Jany (Eds.), Functional approaches to language (pp. 31-69). Amsterdam: Benjamins.

Itkonen, E. (2016). An assessment of (mentalist) cognitive semantics. Public Journal of Semiotics 7/1, 1-42.

Itkonen, E. (2018). In defense of traditional semantics (and against all-out psychologism). Homepage.

Itkonen, E. (2019). Concerning the scope of normativity. In Mäkilähde et al. (Eds.), pp. 2966.

Johnson, M. (1987). The body in the mind: The bodily basis of meaning, imagination, and reason. Chicago: The University of Chicago Press.

Johnson, M \& Lakoff, G. (2002). Why cognitive linguistics requires embodied realism. Cognitive Linguistics 13/3, 245-263.

Johnson-Laird, P. N. (1982). Formal semantics and the psychology of meaning. In S. Peters \& E. Saarinen (Eds.), Processes, beliefs, and questions (pp. 1-68). Dordrecht: Reidel.

Kahneman, D. (2011). Thinking, fast and slow. London: Allen Lane.

Katz, J. (1981). Language and other abstract objects. Oxford: Blackwell. 
Kneale, M. (1970). Dreaming. In Knowledge and necessity: Royal Institute of Philosophy Lectures, Vol. 3 (pp. 236-248). London: Macmillan.

Kroy, M. (1976). Mentalism and modal logic. Wiesbaden: Athenaion.

Labov, W. (1972). Sociolinguistic patterns. Philadelphia: University of Pennsylvania Press.

Lakoff, G. (1987). Women, fire, and dangerous things. Chicago: The University of Chicago Press.

Lehrer, K. (1974). Knowledge. Oxford: Clarendon Press.

Lewandowska-Tomaszczyk, B. (2007). Polysemy, prototypes, and radial categories. In D. Geeraerts \& H. Cuyckens (Eds.), The Oxford handbook of cognitive linguistics. (pp. 139-169). Oxford : Oxford University Press.

Lévi-Strauss, C. (1991). Histoire de lynx. Paris: Plon.

Mäkilähde, A., Leppänen, V. \& Itkonen, E. (Eds.) (2019). Normativity in language and linguistics. Amsterdam: Benjamins.

Meillet, A. (1921). Linguistique historique and linguistique générale. Paris: H. Champion.

Mundle, C.W.K. (1970). Philosophical behaviourism. Knowledge and necessity: Royal Institute of Philosophy Lectures, Vol. 3 (pp. 119-131). London: Macmillan.

Pajunen, A. \& Itkonen, E. (2019). Intuition and beyond: A hierarchy of descriptive methods. In Mäkilähde et al. (Eds), pp. 213-235.

Pap, A. (1958). Semantics and necessary truth: An inquiry into the foundations of analytic philosophy. New Haven: Yale University Press.

Pascal, B. (1972/c. 1657). Pensées. Paris: Librairie Générale Française.

Plato (1963). Collected dialogues. Edited by E. Hamilton \& H. Cairns. Princeton: Princeton University Press.

Popper, K. (1979). Objective knowledge: an evolutionary approach. Oxford: Clarendon Press.

Quine, V. van O. (1967/1953). From a logical point of view. Cambridge, MA: Harvard University Press.

Rakova, M. (2002). The philosophy of embodied realism: A high price to pay? Cognitive linguistics 13/3, 215-244.

Ricken, U. (1988). Le problème de la métaphore et la controverse sur l'imagination à l'âge classique. In Recherches sur la philosophie et le langage 9: La métaphore (pp. 120137). Université des Sciences Sociales de Grenoble.

Russell, B. (1946). History of Western philosophy. London: Allen \& Unwin.

Russell, B. (1962/1940). An inquiry into meaning and truth. Harmondsworth: Penguin Books.

Russell, J. 1984. Explaining mental life: Some philosophical issues in psychology. London: Macmillan.

Searle, J. R. (1992). The rediscovery of the mind. Cambridge, MA: The MIT Press.

Thompson, S. A. \& Hopper, P. (2001). Transitivity, clause structure, and argument structure: Evidence from conversation. In J. Bybee \& P. Hopper (Eds.), Frequency and the emergence of linguistic structure (pp. 27-60). Amsterdam: Benjamins.

Thomson, R. (1968). The Pelican history of psychology. Harmondsworth: Pelican Books.

Von Wright, G.H. (1971). Explanation and understanding. London: Routledge.

Von Wright, G.H. (1984). Demystifying propositions. In Truth, knowledge \& modality (pp. 14-25). Oxford: Blackwell.

Whitney, W. D. (1979/1875). The life and growth of language. New York: Dover.

Williams, B. 1978. Descartes: The project of pure enquiry. Harmondsworth: Pelican Books.

Wittgenstein, L. (1958a/1953). Philosophical investigations. Oxford: Blackwell.

Wittgenstein, L. (1958b). The blue and brown books. Oxford: Blackwell.

Wittgenstein, L. (1967/1956). Remarks on the foundations of mathematics. Oxford: Blackwell. 
Wittgenstein, L. (1980). Remarks on the philosophy of psychology, Vol. II. Oxford: Blackwell.

Zlatev, J. (2008a). The coevolution of intersubjectivity and bodily mimesis. In J. Zlatev et al. (Eds.), The shared mind: Perspectives on intersubjectivity (pp. 215-244). Amsterdam: Benjamins.

Zlatev, J. (2008b). The dialectics of consciousness and language (Editorial introduction). Journal of Consciousness Studies 15/6, 5-14.

Zlatev, J. (2008c). The dependence of language on consciousness. Journal of Consciousness Studies 15/6, 34-62.

Zlatev, J. (2010). Phenomenology and cognitive linguistics. In D. Schmicking \& S. Gallagher (Eds.), Handbook of phenomenology and cognitive science (pp. 415443). Berlin: Springer.

Zukav, G. (1980). The dancing wu li masters: An overview of the new physics. Glasgow: Fontana Paperbacks.

Author Address

E-mail address: eitkonen@utu.fi

About the author

Esa Itkonen (born in 1944), now retired, was 1982-2012 Professor of General Linguistics at the University of Turku (Finland) and 1988-2012 Docent of Philosophy at the University of Jyväskylä (Finland). His main research interests are philosophy/methodology of linguistics, history of linguistics, and linguistic typology. 